\title{
The Role of Special Epilepsy Nurse in Epilepsy Monitoring Unit
}

\section{Maryam Izadi Laybidi*}

Department of Neurology, Esfahan Neurosciences Research Center, School of Medicine, Isfahan University of Medical Sciences, Isfahan, Iran

*Corresponding author: Laybidi MI, Department of Neurology, Esfahan Neurosciences Research Center, School of Medicine, Isfahan University of Medical Sciences, Isfahan, Iran, Tel: + 989133002820; E-mail: maryam.izadi91@yahoo.com

Received date: February 24, 2018; Accepted date: April 27, 2018; Published date: May 03, 2018

Copyright: $\odot 2018$ Laybidi MI. This is an open-access article distributed under the terms of the Creative Commons Attribution License, which permits unrestricted use, distribution, and reproduction in any medium, provided the original author and source are credited.

\begin{abstract}
Background: Epilepsy is an abnormality in the central nervous system which characterized in recurrent or unprovoked seizures. Nurse care is one of the important specialists for management of the patients. The aims of this study was evaluating role of nurse care on management of patients with epilepsy.

Method: This study is a brief review to evaluate role of nurses in management of patients with epilepsy.

Conclusion: Nurses should improve the quality of patient care: 1- We need to have a plan for increasing the knowledge of ESNS, 2- Government should make a new course in Faculty of Nursing and Midwifery, 3- Develop guide lines for ESNS and prepare appropriate programs.
\end{abstract}

Keywords: Nurse; Epilepsy; Care; Epilepsy monitoring unit

\section{Introduction}

Epilepsy is an abnormality in CNS that characterized by recurrent seizures [1] due to abnormal, excessive or synchronous neuronal activity in the brain [2]. Epilepsy can be best understood as a group of syndromes with vastly divergent symptoms all involving episodic abnormal electrical activity in the brain. Nurse care in Epilepsy is useful in assessing symptoms, diagnosis, tests and risk management [3].

Epilepsy Nurses are a part of professional care system which has a man role to manage and evaluate of patients with complex uncontrolled Epilepsy. These nurses can manage diagnosing and changing antiepileptic drug of patents [4]. So epilepsy nurses have mainly effect with highly useful [5]. Same studies, evaluated effect of nurses on patients with epilepsy that demonstrated epilepsy monitoring with Acute Care Nurse Practitioner (ACNP) can effect on patient outcomes, staying in the hospital, costs, decreasing the number of laboratory test and satisfaction of patients [6]. So epilepsy patients need to chronic treatment by primary care that this care included an epilepsy neurologist and epilepsy nurses [7]. The roles of Epilepsy nurses is included dissemination of performing Epilepsy Audit towards creation of a profile of Epilepsy, accurate information to the clients to care better and improving treatment plans and goals [8].

The role of epilepsy special nurse (ESN) has developed significantly over the past twenty years. We are delighted to be able to reply our work.

One of the testing of EEG is video EEG monitoring which records video and brain waves in seizures. Also it's a helpful device to determine type of seizure and following select a suitable treatment by doctor. The patients need Video EEG Monitoring least 4 to 6 days in hospital. Also the stay of patients maybe takes more than 6 days. The episodic events may diagnose by video EEG monitoring but these episode events don't occur in fainting or black-out spells, epileptic seizures, events of unknown origin, hallucinations, confusion or behavioral challenges. In this monitoring, patients stay in room by video EEG, also the epilepsy nurse support patients in the all of the times. The epilepsy monitoring unit (EMU) rooms have private bathroom and a pull out couch. The beds have two padded side rails for safety of patients because the risk of falling in these patients is high and nurse must ensure of safety of bed. In the monitoring of patients with epilepsy, the nurses don't use cigarette or smoking or mobile [9].

\section{The steps of EEG for nurses include}

Nurse must be marking the electrode places with a red pencil.

Marked place must be clean with minimally abrasive skin prep.

30 electrodes are used with Collodion glue (with strong odor and without allergy).

The nurse activities are controlled with EEG technician every day for doing specific activations (photic stimulation and hyperventilation).

A nurse is assisted to patients for use of stationary bike pedals.

Video EEG is checked every day with epileptologist.

When Patients come to the hospital, they should go to:

Admitting department Kashani hospital

After admission, they will go to the EMU at hospital

What will happen when I get to EMU

We will prepare them. So we can monitor their epilepsy

There are 3 steps to prepare them:

A nurse will show their room and the unit. The nurse will then ask them some questions.

Ask you about their medical history.

Do a physical exam. 
Citation: Laybidi MJ (2018) The Role of Special Epilepsy Nurse in Epilepsy Monitoring Unit. Epilepsy J 4: 1000124. doi:

Page 2 of 3

Talk to them about the plan for their cure by epileptolgist (the neurologist who specializes in epilepsy).

A nurse will attach small metal disks (electrodes) to their sculp. They do this with special glue and cream. These electrodes help us to monitor their brain microphone to record their seizures.

\section{What will happen when patients get a seizure?}

They will push a bottom if you feel a seizure starts recording what is happening. It also sends a signal to the nurses.

\section{How long will patients stay?}

Your stay may be 6 days; you will stay until we can record enough seizures.

\section{What should a patient do during their stay?}

They will spend most of time in bed or in a comfortable chair.

They will need to stay in the epilepsy monitoring unit (EMU) area to record seizure.

This is also for their safety.

Every day we will check their electrodes and add cram if needed.

Who will care for them?
Nurses are the main people responsible for their care every day.

They will respond to their needs right away.

\section{Things to do for them}

- Check them regularly

- Respond to their call bell

- Watch you through a monitor

- Select normal and abnormal EEG

The epileptologist will manage your cure and changes their medicines, if needed.

Doctor may decide to reduce the amount of medicine or cut it out.

This will give the team the better chance to record seizure.

\section{Other tests they may get}

Patient may need other tests to help us understand.

\section{What is happening in their brain?}

Neuropsychological tests of memory and language (Table 1). These tests will take about 5 to 7 hours. They will help to find where their seizures are coming from (Table 2).

\begin{tabular}{|c|c|c|}
\hline \multirow{9}{*}{ During the seizure } & \multirow{2}{*}{ Safety } & Ensure patients safety. \\
\hline & & Note the time when the seizure began. \\
\hline & \multirow{4}{*}{ responses } & Give simple command. \\
\hline & & Show patients some object. \\
\hline & & Ask patients to say the names of the objects. \\
\hline & & Tell the patients to remember the objects. \\
\hline & \multirow[b]{2}{*}{ Speech } & Ask the patient to tell a word. \\
\hline & & Tell the patient to remember a word and ask the patient to repeat the word again. \\
\hline & Motor & Observe the location, quality and duration of movements. \\
\hline \multirow{7}{*}{ After the seizure } & \multirow[b]{5}{*}{ Postictal } & Note the time seizure ended. \\
\hline & & Note length of time to recover. \\
\hline & & Observe the postictal behaviour. \\
\hline & & Ask the patient if always same type of seizure is happening. \\
\hline & & Ask the patient if he had been aura of warning. \\
\hline & \multirow[b]{2}{*}{ Memory } & Ask the patient to recall the objects. \\
\hline & & Ask the patient to recall the words. \\
\hline
\end{tabular}

Table 1: Neuropsychological tests of memory and language.

Magnetic resonance imaging (MRI) takes pictures of the brain. You may need an MRI before they leave the hospital or they may need to come back for this test.
When we record enough seizures, they will start taking their medicine again. We will stop the EEG recording and make them ready to go home.

\section{What happens when the monitoring is finished?}


Citation: Laybidi MJ (2018) The Role of Special Epilepsy Nurse in Epilepsy Monitoring Unit. Epilepsy J 4: 1000124. doi: 10.4172/2472-0895.1000124

Page 3 of 3

\begin{tabular}{|c|c|c|}
\hline \multirow{6}{*}{$\begin{array}{l}\text { During the seizure } \\
\text { event: }\end{array}$} & 1. Time seizure event began. & 1. (Document time of event) \\
\hline & 2. Did the patient have an aura or warning prior to the event? & 2. (Choose: Yes/No) \\
\hline & 1. Was the patient able to follow a command? & 1. $(\mathrm{Yes} / \mathrm{No})$ \\
\hline & 2. Was the patient able to identify an object? & 2. (Yes/No) \\
\hline & 3. Was the patient able to repeat a word? & 3. (Yes/No) \\
\hline & 4. Describe the location, type, and duration of any motor activity during the seizure? & 4. (Free text description \\
\hline \multirow{6}{*}{ After the seizure event: } & 1. Time seizure event ended. & 1. (Time event ended) \\
\hline & 2. What was the length of time for the patient to recover to their pre-seizure baseline? & 2. (Length of time to recover) \\
\hline & 3. Was the patient able to recall the command? & 3. (Yes/No) \\
\hline & 4. Was the patient able to recall the object? & 4. (Yes/No) \\
\hline & 5. Was the patient able to recall the word? & 5. (Yes/No) \\
\hline & 6. Describe postictal behaviour in detail. & 6. (Free text description) \\
\hline
\end{tabular}

Table 2: Patient test report during and after the seizure event.

The nurse will set up a follow up appointment for them to see. Your neurologist in the epilepsy clinic at the appointment will talk about the test results and make pass.

If surgery can help your seizures, you will have an appointment with a neurosurgeon that is specialized in epilepsy surgery.

\section{Recommendations}

Nurses should improve the quality of patient care:

- We need to have a plan for increasing the knowledge of ESNS

- Government should be make a new course in master university nursing

- Develop guide lines for ESNS and prepare appropriate program

\section{References}

1. Blume WT, Luders HO, Mizrahi E, Tassinari C, van Emde Boas W, et al. (2001) Glossary of descriptive terminology for ictal semiology: report of the ILAE task force on classification and terminology. Epilepsia 42: 1212-1218.

2. Fisher RS, van Emde Boas W, Blume W, Elger C, Genton P, et al. (2005) Epileptic seizures and epilepsy: definitions proposed by the International
League Against Epilepsy (ILAE) and the International Bureau for Epilepsy (IBE). Epilepsia 46: 470-472.

3. Ridsdale L, Kwan I, Morgan M (2003) How can a nurse intervention help people with newly diagnosed epilepsy?: A qualitative study of patients' views. Seizure-Euro J Epilepsy 12: 69-73.

4. Hosking P (2003) Prescribing and the epilepsy specialist nurse. SeizureEuro J Epilepsy 12: 74-76.

5. Scambler A, Scambler G, Ridsdale L, Robins (1996) Towards an evaluation of the effectiveness of an epilepsy nurse in primary care. Seizure-Euro J Epilepsy 5: 255-258.

6. Sarkissian S, Wennberg R (1999) Effects of the acute care nurse practitioner role on epilepsy monitoring outcomes. Outcomes Manag Nurs Pract 3: 161-166.

7. McElroy-Cox, Caitlin MN, ANP-C, BSN (2007) Caring for patients with epilepsy. The Nurse Practitioner 32: 34-40.

8. Tan JH, Wilder-Smith E, Lim ECH, Ong BKC (2005) Frequency of provocative factors in epileptic patients admitted for seizures: a prospective study in Singapore. Seizure-Euro J Epilepsy 14: 464-469.

9. Atkinson M, Hari K, Schaefer K, Shah A (2012) Improving safety outcomes in the epilepsy monitoring unit. Seizure-Euro J Epilepsy 21: 124-127. 